\title{
IMPORTAÇÕES PARALELAS E EXAUSTÃO DE DIREITOS: UMA VISÃO CRÍTICA
}

Ludmila Arruda Braga ${ }^{1}$

\section{RESUMO}

Este artigo analisa as conseqüências das importações paralelas no Brasil e no mundo sob um prisma crítico, bem como as suas repercussões na Doutrina da Primeira Venda - a exaustão de direitos - e na noção de consentimento. $O$ presente estudo também examina o tratamento conferido ao tema pelo sistema normativo brasileiro e pela jurisprudência.

\section{ABSTRACT}

This paper analyses the implications of permitting the parallel trades on a regular basis in Brazil and around the world by a critical point of view, as well as its implications on the First Sale Doctrine - the exhaustion of rights - and on the principle of consent. This paper also analyses the subject through the brazilian regulatory system and case studies.

Indicadores: PROPRIEDADE INTELECTUAL - IMPORTAÇÕES PARALELAS - EXAUSTÃO DE DIREITOS

\section{CONSIDERAÇÕES PRELIMINARES}

Os direitos de propriedade intelectual têm por escopo a defesa dos frutos advindos da atividade intelectual nos domínios industrial, científico, literário e artístico. Classicamente, subdivide-se a propriedade intelectual em dois conjuntos, quais sejam, os direitos autorais e a propriedade industrial.

\footnotetext{
${ }^{1}$ Advogada. em Direito pela Universidade Federal do Paraná.
}

Revista Brasileira de Direito Internacional, Curitiba, v.4, n.4, jul./dez.2006 
Embora as origens da proteção da propriedade intelectual remontem à Antigüidade, a sua importância só foi consolidada após a percepção do seu grande valor econômico e comercial, impulsionando o desenvolvimento tecnológico e econômico dos Estados na modernidade.

Daí a importância de se resguardarem os direitos de propriedade intelectual através de acordos e convenções internacionais, dentre os quais podemos citar as Convenções de Paris e Berna (reunidas em 1892 sob os BIRPI - Bureaux Internatinaux Réunis Pour la Protection de la Proprieté Intellectuelle), a OMPI (Organização Mundial da Propriedade Intelectual), criada em 1967, e o acordo TRIPS (1994), desenvolvido para suprir as deficiências apresentadas pela OMPI.

Em tempos de globalização, a proteção aos direitos de propriedade intelectual ganha ainda mais relevância, por estimularem o desenvolvimento econômico e o comércio internacional. É neste contexto que se destacam as importações paralelas, que envolvem o comércio de produtos originais, de um país para outro, realizado fora dos circuitos exclusivos de distribuição daqueles produtos.

Os litígios decorrentes desta prática são diversos, na medida em que estimula a competição entre empresas que vendem o mesmo produto, ainda mais quando se leva em consideração que os produtos oriundos de importações paralelas são vendidos a preços inferiores, em decorrência de uma série de fatores que reduzem os custos daquele produto.

É sob este enfoque que se analisará o tema das importações paralelas no ordenamento jurídico brasileiro, abordando os diversos prismas que incidem sobre a questão.

\section{AS IMPORTAÇÕES PARALELAS (GRAY MARKET)}

As importações paralelas - também chamadas de gray market ou, em português, "mercado cinza" - envolvem a comercialização de produtos legítimos em território nacional, a preços inferiores, por terceiros não licenciados pelo titular do direito de propriedade intelectual; portanto, a 
comercialização se dá fora dos circuitos de distribuição exclusiva. Tais produtos são legitimamente comercializados em território estrangeiro, seja pelo próprio titular ou com seu consentimento, seja por licenciados e autorizados.

Antes de se aprofundar no tema, necessário tecer algumas considerações preliminares acerca do termo "mercado cinza".

Primeiramente, o termo não faz referência a mercadorias contrafeitas; as mercadorias provenientes deste meio são legítimas e originais, não tendo relação alguma com a pirataria.

Um segundo aspecto que deve ser analisado é que tais produtos não são originários de contrabando, mas $\operatorname{sim}$ de terceiros que detêm 0 consentimento, a licença ou a autorização para revender estes artigos em seus territórios; portanto, não há configuração de contrabando, mas sim de uma simples operação de compra/venda e exportação/importação de tais produtos.

Por último, destaca-se que o baixo preço destes produtos não está necessariamente atrelado ao baixo valor declarado em nota fiscal, mas sim a uma série de outros fatores, tais quais: o baixo preço da mercadoria no local da compra, em comparação com o preço praticado em território local; o aproveitamento por parte deste comerciante dos investimentos feitos pelo licenciado no país (como, por exemplo, os investimentos em publicidade); o fato de não ter que arcar com custos de assistência técnica; vantagens cambiais, entre outros fatores.

Feitas estas considerações, é possível desvendar vários cenários em que a importação paralela se desenvolve. Cláudia Marins Adiers $^{2}$ elenca três situações diversas em que ocorrem as importações paralelas, a saber:

a) quando uma empresa nacional compra ou licencia os direitos de uma marca estrangeira para fabricar determinado produto em território nacional e um importador, fazendo concorrência com este, importa este mesmo produto com dita marca;

b) quando uma empresa estrangeira é licenciada pelo titular da marca do mercado local para registrar e explorar a marca em outro território, mas

\footnotetext{
${ }^{2}$ ADIERS, Cláudia Marins. "As importações paralelas à luz do princípio de exaustão do direito de marca e seus reflexos nos direitos contratual e concorrencial". Revista de Direito Mercantil. São Paulo, nำ127, pp.128, julho-setembro de 2002.
}

Revista Brasileira de Direito Internacional, Curitiba, v.4, n.4, jul./dez.2006 
acaba por exportar este produto para o mercado nacional, concorrendo com o próprio licenciador;

c) quando o licenciado é empresa afiliada ou controlada pelo titular da marca, e a empresa controladora exporta os produtos para o mercado local, concorrendo com o licenciado local;

Estas situações demonstram o quão amplos são os efeitos das importações paralelas no plano jurídico, verificados tanto no campo do direito de propriedade intelectual como também no do direito consumerista e concorrencial. Não raro, alguns cenários apresentam verdadeira concorrência desleal, como no caso da competição intramarcas.

Um simples exemplo ilustra bem esta situação: três empresas ( $A, B$ e C) vendem o mesmo produto ("x"). A é licenciada não exclusiva e B é integrante do grupo empresarial titular dos direitos de " $x$ " - em ambos casos, tanto A quanto B fazem parte do canal de distribuição exclusiva do produto para o território nacional e, ainda que haja a concorrência intramarca neste caso, elas terão encargos e custos semelhantes para colocar o produto no mercado. Neste caso, a concorrência se dará em campos que ofereçam uma vantagem adicional ao consumidor, tais como assistência técnica e tempo de garantia do produto. C, por sua vez, é terceiro que importa o produto de um licenciado exclusivo em Taiwan, e o revende no mercado nacional por preço 30 \% inferior, o que contribui ainda mais para a concorrência intramarcas. Apesar da problemática ora exposta ultrapassar a proposta do presente estudo, ela é válida por demonstrar a complexidade do tema em questão.

As repercussões das importações paralelas não se restringem, entretanto, à questão concorrencial; repercute também no campo contratual e da propriedade industrial. Conforme José Carlos Tinoco Soares ${ }^{3}$ :

\footnotetext{
“A importação é, sem quaisquer sombras de dúvidas, a maneira mais primitiva e também mais objetiva do industrial e/ou comerciante tomar conhecimento do que se produz além de suas fronteiras. E exatamente por ela é que se estreitam as relações dos mais variados e diversos países, sendo que o elo de ligação entre os povos, entre os governos, entre os industriais e os
}

\footnotetext{
${ }^{3}$ SOARES, José Carlos Tinoco. Tratado de propriedade industrial: marcas e congêneres.São Paulo: Editora Jurídico-Brasileira, 2003, pp.669.
}

Revista Brasileira de Direito Internacional, Curitiba, v.4, n.4, jul./dez.2006 
consumidores, é indiscutivelmente, a "marca" que assinala e distingue os produtos".

Já com relação à patente, é no campo farmacêutico em que mais nitidamente se auferem as repercussões das importações paralelas, senão vejamos:

\begin{abstract}
"For example, if Pfizer or a subsidiary or licensee sells product X in the U.S and Canada, then imports of the same product from Canada into the U.S should be allowed with no additional regulatory approval of the product. In the European Union, parallel trade in medicines is not only legal, but in many respects encouraged, as a mechanism to create a more efficient European market. In some regions of Europe, parallel trade accounts for almost 20\% of products utilized". ${ }^{4}$
\end{abstract}

Por último, interessante notar que as importações paralelas envolvem dois pólos diametralmente opostos: de um lado, aqueles que pretendem preservar seu direito à comercialização exclusiva do produto, pois detentores ou licenciados da propriedade intelectual; de outro, a liberdade de comércio, da livre circulação de bens e serviços e o direito dos consumidores de usufruírem os resultados advindos de um mercado em que prevalece a concorrência.

Nesta esteira, para que compreendamos a fenômeno das importações paralelas, é curial destacarmos dois outros temas: o da exaustão do direito de propriedade intelectual e o problema do consentimento. Tais temas serão objeto dos próximos tópicos.

\title{
3 EXAUSTÃO DE DIREITOS
}

A exaustão de direitos - também conhecida como "First Sale Doctrine" - constitui-se em um mecanismo de limitação ao direito exclusivo de exploração por parte do proprietário do produto. Os direitos decorrentes deste

\footnotetext{
${ }^{4}$ Em português: "Por exemplo, se a Pfizer, ou uma de suas subsidiárias ou licenciadas, vende o produo X nos EUA e no Canadá, então a importação deste produto do Canadá para os EUA deve ser permitida sem maiores marcos regulatórios. Na União Européia, as importações paralelas de medicamentos não só é legal como incentivada, por ser um mecanismo de criação de um mercado europeu mais eficiente. Em algumas regiões da Europa, as importações paralelas respondem por quase $20 \%$ dos produtos consumidos".LOVE, James e FLYNN, Sean. Legal and Policy Issues Concerning Parallel Trade(aka Re-Importation) of Pharmaceutical Drugs in the United States, (online). Disponibilidade: http://open.imshealth.com/IMSinclude/iarticle20021030.asp. Data de acesso: 26/06/2005.
}

Revista Brasileira de Direito Internacional, Curitiba, v.4, n.4, jul./dez.2006 
produto apenas aproveitam ao titular até o momento em que este é colocado, pela primeira vez, no mercado; uma vez colocado no comércio, esgotam-se os direitos do titular relativos a tal produto. Tal mecanismo é um reflexo da finalidade do Direito de Propriedade Intelectual, pois ao mesmo tempo em que se protege 0 titular dos direitos originários de certo produto, evita-se 0 monopólio de tais direitos e um possível prejuízo ao mercado e aos consumidores.

Logo, uma vez feita a primeira comercialização e esgotados os direitos sobre aquele produto naquele mercado para seu titular, a este não é mais possível proibir ou restringir a comercialização da mercadoria por terceiros, de acordo com o regime de liberdade de comércio. Assim sendo, não seria lícito ao titular se insurgir contra as "importações paralelas", uma vez exauridos os direitos sobre aquela mercadoria.

Contudo, é importante ressaltar que a exaustão só se dará quando este produto seja legitimamente posto no mercado, ou seja: quando é o próprio titular, ou um terceiro com o seu consentimento, que o coloca no comércio. Caso a primeira venda seja feita por um terceiro não-autorizado, inexistente a exaustão. Outra hipótese de não exaustão é quando a colocação do produto no mercado afetou negativamente os legítimos interesses do proprietário dos direitos do produto em questão; isto ocorre nos casos em que um terceiro, presumindo o consentimento do titular, toma a iniciativa de fazer a primeira venda.

Desta forma, a ocorrência da exaustão de direitos importa na análise de dois requisitos, a saber: a) a questão do consentimento do titular; b) a questão da amplitude geográfica.

O primeiro requisito será tema de tópico próprio. O segundo importa na análise da exaustão em três níveis: internacional, nacional ou regional. Quanto a isto, frise-se que o acordo TRIPS deixa a questão em aberto, relegando aos Estados a disposição normativa sobre a matéria, conforme reza o art. 6으, in verbis:

Revista Brasileira de Direito Internacional, Curitiba, v.4, n.4, jul./dez.2006 
"Para os propósitos de solução de controvérsias no marco deste Acordo, e sem prejuízo do disposto nos Artigos 3 e 4, nada neste Acordo será utilizado para tratar da questão da exaustão dos direitos de propriedade intelectual".

Logo, desde que obedecidos os limites mínimos estabelecidos pelo TRIPS (aqui, o dispositivo refere-se expressamente aos artigos 3 e 4, respectivamente, o "princípio do tratamento nacional" e o "princípio da nação mais favorecida"), é dado ao legislador de cada Estado reger a matéria da maneira que melhor convier aos interesses nacionais.

A exaustão nacional ocorre quando o direito de exclusividade se exaure somente dentro dos limites de um Estado; assim, a primeira venda de um produto no Brasil não faz com que seja possível a venda deste por terceiros no Paraguai, pois a exaustão está limitada ao território nacional. De fato, o Brasil adota a exaustão nacional dos direitos de propriedade intelectual, o que nos confere um nível mais alto de proteção, além de estimular a produção local e a transferência de tecnologia (Lei no 9.279/1996, art.43, IV).

A exaustão internacional ocorre da mesma forma: uma vez colocado o produto no mercado, está o titular impedido de restringir ou proibir o comércio do produto em qualquer parte do mundo. Se por um lado o esgotamento internacional é menos protetivo, por outro, estimula a competitividade. Segundo Carlos Correa, citado por Maristela Basso ${ }^{5}$ :

\footnotetext{
"O reconhecimento do princípio do esgotamento internacional do Acordo TRIPS pode ser visto como um reflexo lógico da globalização da economia em nível nacional. Esta solução é conveniente para assegurar a competitividade das empresas locais, que podem estar em desvantagem se se vêem obrigadas a comprar exclusivamente de distribuidores que aplicam preços mais altos que os vigentes em outro país".
}

Por fim, a exaustão regional é aquela verificada na União Européia. Uma vez colocado o produto no mercado, não é mais permitido ao seu titular restringir as ulteriores vendas do bem dentro dos limites da União. Este entendimento foi construído jurisprudencialmente com base nos artigos 28-30 do Tratado de Amsterdã. Aliás, a ECJ - European Court of Justice - vem debatendo este assunto intensamente, haja vista o grande conflito de

\footnotetext{
${ }^{5}$ BASSO, Maristela. O Direito Internacional da Propriedade Intelectual. Porto Alegre: Livraria do Advogado, 2000, pp. 182.
}

Revista Brasileira de Direito Internacional, Curitiba, v.4, n.4, jul./dez.2006 
interesses envolvido. As decisões da Corte Européia são ora favoráveis às importações paralelas, ora contrárias; a explicação que pode ser dada para esta posição cambiável é o fato de o tema implicar em considerações de múltiplas ordens.

Duas das questões mais debatidas no tribunal europeu são (i) a importação paralela de produto por licenciado/autorizado fora dos limites da União - a questão é se aqui haveria ou não a exaustão, com base no artigo 7 da "Trade Mark Directive" e (ii) a re-embalagem do produto - poderia o terceiro colocar novo invólucro na mercadoria para facilitar a entrada desta no mercado em questão? Ou tal atitude infringiria o direito de marca? Tais considerações recebem tratamento complexo pela ECJ, mas ainda não há posição firme sobre elas, dada a complexidade da matéria. Um exemplo que merece ser citado é o caso da Boehringer Ingelheim KG \& Another v. Swingward Ltd. \& Others ${ }^{6}$, no qual também envolve o problema do consentimento, o qual se passará a analisar no tópico a seguir.

\section{O PROBLEMA DO CONSENTIMENTO}

A questão do consentimento é altamente discutida nos Tribunais de vários países, pois envolve aspectos como a exploração de direitos de propriedade intelectual, licenças de distribuição e fabricação da mercadoria.

O consentimento pode ser tácito ou expresso; a maioria das legislações não determina de que modo ele deva se dar para ser considerado válido. De toda sorte, os problemas se canalizam quando da ocorrência da primeira hipótese, ou seja, quando se supõe a existência de consentimento tem-se entendido, jurisprudencialmente, que devem ser reputadas como consentidas as vendas efetuadas por aqueles vinculados economicamente ou juridicamente ao titular da marca, mas ainda subsistem decisões em sentido oposto. Valesca Raizer Borges ${ }^{7}$ analisa a questão do consentimento sob duas

\footnotetext{
${ }^{6}$ Case 143/00, ECJ.

${ }^{7}$ BORGES, Vanesca Raizer. As Importações Paralelas nas relações regionais: a exaustão dos direitos de propriedade intelectual no debate sobre a Área de Livre Comércio das Américas ALCA, (online). Disponibilidade: www.mundojuridico.adv.br. Data de acesso: 18/06/2005.
}

Revista Brasileira de Direito Internacional, Curitiba, v.4, n.4, jul./dez.2006 
vertentes: uma subjetiva e outra objetiva. Adotaremos o mesmo entendimento para expor a matéria neste artigo.

A vertente subjetiva se baseia nos sujeitos presentes em uma importação paralela, ou seja, nas relações interempresariais que ocorrem entre as sociedades participantes do negócio, sendo possível identificá-la em duas situações distintas: a primeira diz respeito às importações paralelas entre empresas vinculadas (sejam controladas ou participantes do mesmo grupo de sociedade titular do direito de propriedade no local de importação); a segunda ocorre quando a venda no mercado estrangeiro envolve o licenciado ou autorizado do titular do direito de propriedade.

$\mathrm{Na}$ primeira hipótese, quando há uma relação de subordinação entre as sociedades (existindo, neste caso, o poder de controle efetivo de uma sociedade sobre a outra), presume-se a existência do consentimento. Isto porque não haveria, neste caso, autonomia da subordinada com relação à controladora, não sendo possível detectar aí "vontades" diferentes - logo, a partir do momento em que uma subordinada introduz um produto no mercado, ou quando realiza a venda/exportação para uma empresa de outro território, entende-se que tais atos não foram praticados pela subordinada, mas sim pelo próprio titular dos direitos de propriedade; ademais, só faria sentido em se referir a existência ou não de consentimento quando está a se tratar de pessoas ou entes diferentes, o que não é o caso, pois se trata de uma mesma pessoa jurídica. No caso da subordinação, portanto, considera-se esta como uma verdadeira extensão da empresa controladora.

Este é o entendimento que se adota nos EUA; na Europa, ainda que se verifiquem alguns casos em que tal entendimento é recepcionado, subsistem controvérsias. No Brasil, poucas são as decisões envolvendo a questão das importações paralelas e o problema do consentimento: ainda que uma decisão do Supremo Tribunal Federal de 1959 (Recurso Extraordinário o 36.415-SP) tenha seguido a corrente acima, favorável à exaustão de direitos e às importações paralelas nestes casos, é certo que de lá para cá o entendimento tem sido diverso, como na decisão prolatada pelo Tribunal de Justiça do Rio 
Grande do Sul. Esta decisão será analisada no próximo tópico, no qual teremos a oportunidade de estudá-la a luz dos dispositivos nacionais e internacionais.

A segunda hipótese refere-se às importações paralelas entre licenciados, na qual a questão é ainda mais controvertida. Isto porque na maioria dos casos, os obstáculos poderiam ser evitados com cláusulas contratuais específicas que dispusessem sobre a extensão territorial de exclusividade sobre determinado produto, evitando que uma zona territorial, já concedida para a exploração exclusiva de um licenciado, colida com o direito de outro licenciado sobre aquele mesmo território. Este mesmo contrato também disporia de cláusulas sobre a venda/exportação do produto a terceiros não licenciados e a sua comercialização em território diverso, bem como a responsabilização por tais atos de comércio. Entretanto, é certo que, caso o contrato nada disponha sobre estas questões, deverá ser considerada a exaustão dos direitos, pois haverá a presunção de consentimento.

Quanto à vertente objetiva, cuida-se da "qualificação do consentimento tácito" (nas palavras de Valesca Raizer Borges ${ }^{8}$ ). Aqui, importa saber se 0 consentimento refere-se a todos os produtos, idênticos ou similares, ou se este só é válido para aquele que foi objeto da primeira venda. Assim, caso o titular desenvolva alguma alteração no produto (por exemplo: mudança de embalagem), os direitos sobre esta nova mercadoria ainda não teriam sido esgotados. Logo, o entendimento é o de que o consentimento recai sempre e tão somente para cada exemplar do produto.

Além disso, é importante ressaltar que o objeto da importação paralela não pode sofrer alterações que o modifiquem substancialmente, sendo reconhecido ao titular a pretensão de agir judicialmente contra aquele que alterou o produto. Esta última observação é muito importante quando estamos a tratar de produtos farmacêuticos, nos quais simples modificações no envase, por exemplo, podem alterar substancialmente a qualidade do produto, sendo 0 titular responsabilizado pelos malefícios que estes venham a ocasionar nos usuários. Sobre a alteração na embalagem de produtos farmacêuticos, é

\footnotetext{
${ }^{8}$ BORGES, Vanesca Raizer. As Importações Paralelas nas relações regionais: a exaustão dos direitos de propriedade intelectual no debate sobre a Área de Livre Comércio das Américas ALCA, (online). Disponibilidade: www.mundojuridico.adv.br. Data de acesso: 18/06/2005. p .8.
}

Revista Brasileira de Direito Internacional, Curitiba, v.4, n.4, jul./dez.2006 
interessante citarmos dois casos: Bristol-Myers Squibb v. Paranova, $A / S$, (1996), E.C.R I-3457 e Upjohn S.A v Paranova A/S, Case C-379/979. O curioso é que, nestes casos, a ECJ (European Court of Justice) permitiu a reembalagem dos produtos como forma de assegurar, nestes casos específicos, a livre movimentação dos bens na União Européia. Nota-se, portanto, que a matéria em questão admite vários fenômenos jurídicos que, dependendo do caso, podem ou não ser vistos como ilegais. As decisões irão variar conforme as situações colocadas e os dispositivos invocados para a defesa de cada uma das partes. No caso da União Européia, sublinha-se que há também o interesse precípuo de integração econômica; tendo isto em vista, a Corte Européia costuma recepcionar a importação paralela de forma mais ampla, contemplando assim a livre circulação de mercadorias entre os Estados unionistas.

\section{OS TRATADOS INTERNACIONAIS E A LEI DE PROPRIEDADE INDUSTRIAL}

Ao ratificar a Rodada do Uruguai do GATT, o Brasil recepcionou o Acordo sobre Aspectos de Propriedade Intelectual Relacionados com Comércio - TRIPS, incorporado ao nosso sistema através do Decreto Legislativo № 30 de 15/12/94 e do Decreto № 1355 de 30/12/94. A aplicação plena deste Acordo para o Brasil só se deu em 1ํ de janeiro de 2000 e, portanto, posterior a nossa Lei de Propriedade Industrial (Lei 9279/1996). Por ser posterior, uma vez observadas discrepâncias entre o este Acordo Internacional e a nossa Lei, aquele deverá prevalecer. Além disso, salienta-se que o Acordo TRIPS estabelece padrões mínimos de proteção que devem ser respeitados pelas legislações nacionais dos Estados, sob pena de sanções ou, até mesmo, retirada do Estado "infrator" do Acordo.

\footnotetext{
${ }^{9}$ Para ter acesso aos comentários destes casos, ver: HARWOOD, Stephenson. Parallel Imports and the exhaustion of rights: the world focus. Disponibilidade:

www.shlegal.com/docs/parallelimports.pdf
}

Revista Brasileira de Direito Internacional, Curitiba, v.4, n.4, jul./dez.2006 
Feitas estas considerações iniciais, importa analisar os dispositivos destas normas no que diz respeito à exaustão de direitos e importações paralelas.

Comecemos pela LPI. O artigo 68, nos dispositivos que aqui nos interessam, reza que:

\footnotetext{
Art. 68. O titular ficará sujeito a ter a patente licenciada compulsoriamente se exercer os direitos dela decorrentes de forma abusiva, ou por meio dela praticar abuso de poder econômico, comprovado nos termos da lei, por decisão administrativa ou judicial.

$\S 1^{\circ}$ Ensejam, igualmente, licença compulsória:

I - a não exploração do objeto da patente no território brasileiro por falta de fabricação ou fabricação incompleta do produto, ou, ainda, a falta de uso integral do processo patenteado, ressalvados os casos de inviabilidade econômica, quando será admitida a importação;

$\S 3^{\circ}$ No caso de a licença compulsória ser concedida em razão de abuso de poder econômico, ao licenciado, que propõe fabricação local, será garantido um prazo, limitado ao estabelecido no art. 74, para proceder à importação do objeto da licença, desde que tenha sido colocado no mercado diretamente pelo titular ou com o seu consentimento.

$\S 4^{\circ}$ No caso de importação para exploração de patente e no caso da importação prevista no parágrafo anterior, será igualmente admitida a importação por terceiros de produto fabricado de acordo com patente de processo ou de produto, desde que tenha sido colocado no mercado diretamente pelo titular ou com o seu consentimento. (grifos nossos)
}

Enquanto isso, o art.132, III da Lei dispõe que "O titular da marca não poderá (...) impedir a livre circulação de produto colocado no mercado interno, por si ou por outrem com seu consentimento, ressalvado o disposto nos $\$ \S 3^{\circ} e$ $4^{\circ}$ do art. 68".

Deixando de lado a análise sobre a questão das licenças compulsórias, concluímos que:

a) A LPI, seguindo o preceito do artigo 7 do Acordo TRIPS, privilegia a exploração local do produto; a patente é concedida como uma forma de fomentar a economia local e as inovações tecnológicas do território, já que ela também é uma via de difusão de informação;

b) Segundo a Convenção de Paris (CUP) a exploração local do objeto da patente é uma exigência absoluta. A exploração está diretamente atrelada à fabricação local e, portanto, a importação é vista como abuso do direito conferido ao titular da patente (desde que o titular que explora a patente via importação comprove que o faz por justo motivo); 
c) A importação por terceiros (a importação paralela) é proibida em nosso sistema jurídico, salvo duas exceções: a primeira ocorre quando da licença compulsória (aqui, a importação paralela só pode ocorrer durante o período permitido ao licenciado importar tal produto para a fabricação local; no momento em que este começar a explorar/fabricar a patente localmente, proíbe-se novamente a importação paralela); a segunda exceção ocorre quando da inviabilidade econômica para produzir o bem, permitindo-se que terceiros entrem no mercado via importação paralela.

A restrição das importações paralelas só nestes dois casos foi uma forma de estimular a economia local e, principalmente, de evitar o monopólio das importações. Logo, o mercado brasileiro continua a ser atendido, mas agora, sem monopólio.

Entretanto, como já comentado no tópico anterior, os Tribunais brasileiros têm se debatido na questão. Um julgado de 2001 do Tribunal de Justiça do Rio Grande do Sul nos mostra como o problema é controvertido e carece de aprofundamento no meio jurídico nacional. Abaixo, segue transcrita a ementa:

AGRAVO DE INSTRUMENTO. MEDIDA CAUTELAR DE BUSCA E
APREENSAO IMPORTACAO DE PRODUTOS SEM O
CONSENTIMENTO DO TITULAR DA MARCA. DIREITO PROTEGIDO
PELA LEI DA PROPRIEDADE INDUSTRIAL. FERINDO A
IMPORTACAO REALIZADA PELA AGRAVANTE DIREITO
PROTEGIDO PELA LEI DA PROPRIEDADE INDUSTRIAL, CORRETA
A CONCESSAO DE LIMINAR PARA DETERMINAR A BUSCA E
APREENSAO DOS PRODUTOS IMPORTADOS PELO IMPORTADOR
PARALELO SEM O CONSENTIMENTO DO TITULAR DA MARCA.
AGRAVO NAO PROVIDO. (Agravo de Instrumento No 7000265968 ,
Sexta Câmara Cível, Tribunal de Justiça do RS, Relator: João Pedro Pires
Freire, Julgado em 01/08/2001).

No caso acima, a Agravante (Enterprise Indústria Comércio Importação e Exportação Ltda) havia comprado 1880 pares de calçados originais Nike International Ltd., através da Nike Argentina S.A. - Sucursal Nike Uruguay, e sua distribuidora Coltir Trading S.A., sendo aquela autorizada pela primeira a vender e comercializar os produtos. Alegando a exaustão nacional - haja vista que, uma vez colocados no mercado nacional, com o consentimento ou autorização do titular, ocorre o esgotamento dos direitos, e sabendo-se que a 
Nike International Ltd. concedeu a autorização exclusiva para que tal fosse feito somente pela Nike do Brasil Comércio e Participações Ltda. - a Agravante acabou vencida no recurso sob o argumento do Relator de que "a empresa da qual a agravante adquiriu os produtos que importou não está autorizada pela NIKE a promover exportações para o território brasileiro, em observância aos direitos da licenciada exclusiva no Brasil".

Tal decisão merece comentários, à luz dos aspectos subjetivos do problema do consentimento. Se, por um lado, é verdade que a distribuidora uruguaia e a licenciada Argentina não estavam permitidas a vender a mercadoria para empresa brasileira, tendo sido isto pactuado em contrato entre as partes justamente para não prejudicar a autorizada exclusiva brasileira, por outro também o é que, a partir do momento que tal mercadoria entra no mercado nacional via importação da própria Nike do Brasil Comércio e Participações Ltda., há a exaustão de direitos.

Portanto, se este produto não é produzido no Brasil (desatendendo o interesse do país, que the concedeu permissão para explorar o mercado com exclusividade, visando ao fomento da economia local), a legislação nacional confere o direito de que terceiros também importem o produto (conforme 0 artigo $68, \S 1^{\circ}, 1$ e $\S 4^{\circ}$ ), acirrando a concorrência, evitando o monopólio da importação e desenvolvendo o mercado nacional. Deste modo, a atitude mais acertada para o caso seria uma ação da Nike International Ltd. contra a licenciada Argentina e a distribuidora uruguaia, e não contra a importadora brasileira, pois esta agiu em conformidade com o disposto na nossa Lei de Propriedade Industrial. Por fim, ressalte-se ainda que o monopólio conferido à Nike do Brasil Comércio e Participações Ltda. - legitimado por este acórdão acabou por desmerecer o artigo 8.2 da CUP, o qual estabelece que:

Desde que compatíveis com o disposto neste Acordo, poderão ser necessárias medidas apropriadas para evitar o abuso dos direitos de propriedade intelectual por seus titulares ou para evitar o recurso a práticas que limitem de maneira injustificável o comércio ou que afetem adversamente a transferência internacional de tecnologia.

Revista Brasileira de Direito Internacional, Curitiba, v.4, n.4, jul./dez.2006 
Portanto, sem embargo quanto à proteção da propriedade intelectual, deve também ser contemplada a livre circulação de bens e as importações por terceiros, nas hipóteses previstas em lei.

\section{CONCLUSÃO}

As importações paralelas representam um grande desafio para os Estados, pois necessária a compatibilização entre liberdade comercial e proteção da propriedade intelectual. Ainda que existam regras sobre a questão da exaustão de direitos, subsiste ainda o problema do consentimento e das repercussões das importações paralelas no âmbito contratual e concorrencial.

Se de um lado as importações paralelas representam a liberdade de comércio, a livre concorrência e a integração econômica, por outro, é inegável a existência de aspectos questionáveis.

Um dos aspectos mais criticáveis das importações paralelas é que, não raro, ela acarreta no que chamamos de concorrência desleal, que pode se configurar sob duas vertentes: causar prejuízos a terceiros ou gerar, para si, benefícios ilegítimos. A concorrência, através da legislação antitruste, permite que se contestem as posições de mercado conquistadas, assegurando o funcionamento do mercado. Pois bem, o que ocorre é que as importações paralelas acabam por gerar uma competição intramarcas, ou seja: dois ou mais entes competem com o mesmo produto e, como estamos aqui tratando de mercadorias legítimas, a competição se dá só com relação aos preços e vantagens adicionais (como assistência técnica, por exemplo); ainda que esta situação seja ótima para o consumidor a curto prazo, é possível que não o seja dentro de um maior espaço de tempo - como já colocamos neste artigo, as mercadorias originárias de importações paralelas entram no mercado com um preço mais acessível por vários motivos, tais quais baixo preço da mercadoria no território que vende/exporta, vantagens cambiais, etc. Um dos motivos que também ajudam a sustentar o baixo preço destas mercadorias é o fato de elas não investirem em infra-estrutura, propaganda e assistência técnica. Isto 
representa um grande desincentivo às licenciadas e autorizadas, que investem não só para elas, mas também para seus concorrentes.

Quanto à questão do consentimento, a via mais segura para a resolução de controvérsias entre titular, licenciado e autorizado é o contrato. Entretanto, este deve estar em conformidade com os acordos internacionais e as legislações de cada Estado, sob pena de quebrar os princípios regidos nestas normas.

Os Tribunais brasileiros têm se debatido sobre a questão, tendo em vista a recente vigência da lei e as poucas decisões existentes sobre o caso. Ainda que as controvérsias sejam diversas, sublinhe-se que a análise do tema das importações paralelas tem ultrapassado a questão da propriedade intelectual e repercutindo também no âmbito contratual e concorrencial. É bom salientar, contudo, que cada caso merece análise única, não sendo possível ao menos por enquanto - uma uniformização jurisprudencial sobre a possibilidade ou impossibilidade irrestrita das importações paralelas no Brasil. Cada situação assume feições diferentes e, por isso mesmo, merecem decisões também distintas.

Por fim, conclui-se que as importações paralelas são inevitáveis em uma economia globalizada, motivo pelo qual o tema deve merecer tratamento legal e maior acuidade quando objeto de decisões judiciais, pois estas devem não só observar o ordenamento jurídico nacional quanto 0 internacional. Também com relação aos blocos regionais - a exemplo da União Européia - é possível que o Mercosul também tenha que regulamentar tal matéria, a fim de que haja uniformidade dos tribunais deste bloco quanto ao gray market.

\section{REFERÊNCIAS}

ADIERS, Cláudia Marins. "As importações paralelas à luz do princípio de exaustão do direito de marca e seus reflexos nos direitos contratual e concorrencial”. Revista de Direito Mercantil. São Paulo, nำ127, julho-setembro de 2002.

Revista Brasileira de Direito Internacional, Curitiba, v.4, n.4, jul./dez.2006 
AHLERT, Ivan B. Importação Paralela e Licença Compulsória. In: Revista da ABPI, no27. Mar/Abr, 1997. Versão revisada e atualizada disponível em www.ids.org.br/files/ImportacaoParalela.pdf.

BARBOSA, Denis Borges. Uma Introdução À propriedade Intelectual. Rio de Janeiro: Lumen Júris, 2003.

BASSO, Maristela. O Direito Internacional da Propriedade Intelectual. Porto Alegre: Livraria do Advogado, 2000.

BORGES, Vanesca Raizer. As Importações Paralelas nas relações regionais: a exaustão dos direitos de propriedade intelectual no debate sobre a Área de Livre Comércio das Américas - ALCA, (online). Disponibilidade:

www.mundojuridico.adv.br. Data de acesso: 18/06/2005.

COMPARATO, Fábio Konder. O Poder de Controle na Sociedade Anônima, 3a ed, São Paulo: RT, 1983.

HARWOOD, Stephenson. Parallel Imports and the exhaustion of rights: the world focus. Disponibilidade: www.shlegal.com/docs/parallelimports.pdf.

LOVE, James e FLYNN, Sean. Legal and Policy Issues Concerning Parallel Trade(aka Re-Importation) of Pharmaceutical Drugs in the United States,(online).

Disponibilidade:http://open.imshealth.com/IMSinclude/i_article_20021030.asp. Data de acesso: 26/06/2005.

MASKUS, Keith E. Parallel Imports on Pharmaceuticals:implications for competition and pricesin developing countries. Abril, 2001.

Disponibilidade:www.wipo.org/about-ip/em/studies/pdf/ssamaskuspi.pdf.

Revista Brasileira de Direito Internacional, Curitiba, v.4, n.4, jul./dez.2006 
SAMPAIO, José Maria Corrêa de. A problemática das importações paralelas. Artigo publicado no Semanário Económico, setembro de 2003.

SCHOLZE. Simone H. Fabricação local, Licença Compulsória e Importação paralela na Lei da Propriedade Industrial. In: Revista da ABPI, no 54, Set/Out, 2001.

SOARES, José Carlos Tinoco. Tratado de propriedade industrial: marcas e congêneres.São Paulo: Editora Jurídico-Brasileira, 2003.

Revista Brasileira de Direito Internacional, Curitiba, v.4, n.4, jul./dez.2006 